\title{
Building a Supportive Mentoring Network
}

\section{Mary Anne S. Mendoza and Samantha A. Vortherms}

Mentors come in many forms, but all mentors provide various forms of support over the course of our graduate careers. Building a supportive network of faculty, near-peer, and peer mentors both inside your department and the political science community more broadly helps you advance your career and makes the often challenging process of graduate school easier. Mentors provide a range of support, including direct career advice, research guidance, emotional support, and a sense of belonging. Developing a supportive network is important for all graduate students, but is particularly beneficial for graduate students from under-represented backgrounds, as mentors can provide a sense of belonging in an alienating environment and open doors to important resources.

In this chapter, we outline the who, what, where, when, why, and how of building a mentoring network. We argue that you should think of mentorship not as a single relationship between yourself and your advisor, but broadly as a network for support that provides guidance from a variety of sources. We highlight the types of roles mentors can play and provide advice on where to find mentors and existing resources to help you build the support you need to thrive in graduate school and your career.

\section{Who, What, and Why Mentorship?}

Building a mentoring network starts with understanding who "counts" as a mentor. In general, mentors are people we trust to provide advice based on their expertise and experience. 
Academic advisors, and faculty in our department, are often clear candidates for mentors. But these are not the only people that graduate students can turn to for advice. In some cases, graduate students may need multiple mentors for different things and faculty advisors should not be the only source of mentorship for everything. Near-peers - graduate students in older cohorts and postdoctoral fellows — can also be mentors, especially since they understand how to navigate the formal and informal expectations of the program. Peers in the same cohort can also serve as a mentor, because they are colleagues with potentially valuable insight and the shared experience of graduate school. Mentoring involves "sharing experiences, hardships, and knowledge to help others to grow, advance and carry on a legacy" (Marino 2020,748). This means that mentors are all of those around you who provide support based on their past experiences.

Mentorship is often framed as a formal affair where students and faculty are assigned to each other, but not every university sets junior scholars up with mentors. Similarly, most faculty who are willing to work with you are unlikely to proactively seek out mentees and establish a mentorship relationship. This is not because they are uninterested, but because of busy workloads. Therefore, understanding the formal and informal ways that mentorship occurs is useful for junior scholars trying to find mentors.

Formal mentoring — which occurs as an established relationship between a faculty member or senior graduate student and their assigned graduate student - has stated objectives. One prime example is your academic advisor and committee members who, at the very least, provide feedback on your research and sign off on your progress through the degree. Other examples of formal mentorship can be found through opportunities in your department, university, or field when you sign-up for a mentor and are matched with a volunteer. 
Informal mentoring, however, happens more organically and may not always have stated objectives. An informal mentor can be a faculty member not on your committee or a graduate student (near-)peer. These may also be individuals you meet at conference panels, receptions, or doing research. Informal mentoring usually develops naturally as you build professional and personal relationships.

\section{Approaches to Mentorship}

Many students begin their graduate programs with one model of mentorship in mind. They see advisors as intellectual sculptors while expecting guidance and direction from one source. In reality, this is only one form of mentorship. Moreover, it is often not the most effective for all students. Three of the most common forms of mentoring relationships are the master-apprentice model, the hierarchical model, and the network model (Figure 1).

Figure 1: Forms of Mentoring Relationships

(a) Master-Apprentice

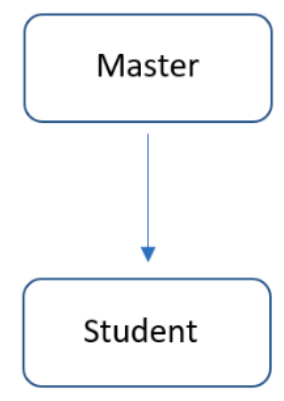

(b) Hierarchical

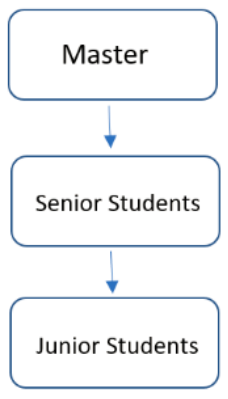

(c) Network

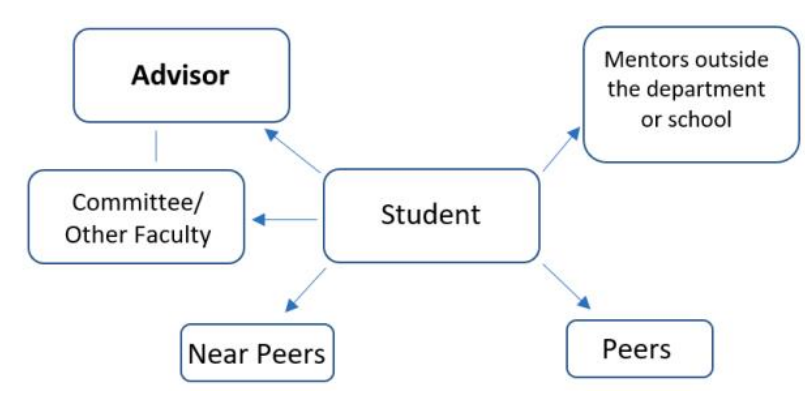

The master-apprentice model ties the student to one mentor who provides all of the mentoring and support the student needs. The hierarchical model builds on this by creating a hierarchy of scholars based on experience within the advisor's group. Lastly, in the network model, students approach a variety of people for mentoring; thus, it is the broadest model. 
While there is no one-type-fits-all model, we believe the network model is the most beneficial for most students. By broadening your mentoring network, you have greater avenues for support and can create a community to support you through the different challenges and phases of graduate school.

\section{Roles Mentors Play}

Mentors play a variety of roles throughout your career, both during and after graduate school, including these common roles:

General mentors include your advisor and committee members or those in your department who have a direct say over the progress of your career. An advisor provides the most direct feedback on one's work and career progress. Other faculty members, on and off your committee, can also advise you on a wide variety of topics such as setting deadlines for timely completion of program requirements, providing direction on research papers, or resolving inclassroom difficulties when teaching.

A subject expert is someone who knows your research area well. Subject experts are helpful at directing you to case-specific literature and understanding your case or topic more broadly.

Methodological experts are mentors who can help you complete your research design or approach. These mentors help you identify appropriate methodological approaches, gain skills for methods, and review results.

A faculty advocate uses their position to advocate for your interests or individual concerns. Advocates often know you or your situation well. We contend that advocates serve to ensure that you, as a person, are valued beyond your research input. Universities can have 
complex systems of governance and advocates help you navigate the institutional structures that exist to provide you with the best support.

Readers are people willing to read your work and give you substantive feedback at different stages. Final products, whether dissertation chapters, articles, or books, never get published without the feedback of multiple readers. In earlier years, readers largely come from your institution, but in later years it is helpful to have readers from outside your department to provide new perspectives. Faculty members can all be readers, but near-peer and peer mentors are also invaluable. If you are particularly concerned about your work being "ready" to submit somewhere, near-peer mentors can help you address early-stage problems so that your advisors can focus on higher-level feedback. Students from under-represented groups benefit disproportionately from peer mentoring through reading and writing groups (Cassese and Holman 2018). Readers can be further broken down by the type of feedback they give.

- Napkin Readers help you brainstorm, such as sketching out an argument on a napkin over a coffee. They are great at asking questions about your ideas and push you to think about your work in a different light.

- $\quad$ The Cheerleader is good at positive reinforcement. Many times, the Cheerleader can see your work contextualized in ways that you cannot, identifying how your research speaks to a broader audience.

- $\quad$ The Critic is a reader who provides a hard-hitting assessment of your work. They identify weaknesses in your argument or methodological approach while also helping you overcome them.

- The Specialist knows your area of study well. They provide the first "sniff" test - an informal reality check — of an idea or an argument. 
- Line-by-Line readers help us polish language and clarify our arguments. They are willing (and able!) to read your writing closely to edit grammar while also helping clarify language so your argument comes across clearly.

Older sibling mentors are graduate students in advanced cohorts who have already experienced the stages of the program that lie ahead of you. These mentors provide invaluable institutional knowledge ranging from logistical questions, such as how to get conference travel reimbursed, to what it's like working with certain faculty members. Older sibling mentors have been there, in your department, and can share their experiences.

Graduate school and academic life is challenging for any number of reasons. One of the essential peer-mentor roles is that of emotional supporters. While some graduate students are prone to competition, the role of an emotional support mentor is to listen empathetically, make space for your concerns, and validate your experiences. Graduate students from other institutions can be especially valuable sources of emotional support, since they can empathize with your experience without knowing the members of your department as intimately.

Accountability mentors are those who help keep you on track and get your work done, so that projects move forward. There are many ways to do accountability groups in graduate school: sitting down to write together, email check-ins, sharing to-do lists, or setting deadlines and follow-ups. Find a way that works for you and surround yourself with people who help you keep your momentum up.

\section{Why It Matters}

Mentors provide information about the broad process of graduate school and developing as a scholar because they have been there. Mentors gained their experience through learning from or collaborating with others and can introduce you to other scholars in the field, point out 
useful resources, and identify other potentials for your research. Based on their experiences, they help mentees overcome obstacles and prevent unnecessary challenges. For example, research shows engaging in mentoring networks improves women's likelihood of obtaining a faculty position (Argyle and Mendelberg 2020). Peer mentoring also improves professional, learning, social, and psychological outcomes for students (Fugate, Jaramillo, and Preuhs 2001; Lorenzetti et al. 2019).

Mentors can provide invaluable insight into how to navigate unknown experiences, such as the importance of having an elevator speech or what to do if a more senior person is being untoward at a reception. Students, especially from under-represented backgrounds, may not always have the privilege of knowing the expected behaviors in certain situations, making this knowledge sharing even more important. For some students, mentors can also help them navigate and challenge the limits of how to "present" oneself, especially when academia places additional expectations on students of color or LGBTQ+ individuals. This volume includes several chapters on concerns for individuals of particular groups, please see the section on strategies for addressing implicit bias, harassment, and assault.

Moreover, mentors also benefit from these relationships. For senior mentors, mentees are rising stars with new and interesting perspectives. Mentees help expose mentors to cutting edge research topics, methods, and innovative teaching. Many of us love working with graduate students, helping them progress through the field. Peer mentors also gain substantially from engaging in relationships, as support is mutually constituted.

\section{Where to Find Mentors}

Just like the various roles for mentors, there are a range of places to look for mentorship. The first place to develop your mentoring network is within your department. The faculty in your 
department should form the core of your general mentoring network. Practically speaking, they are gatekeepers who monitor and approve your progress through the program.

colleagues in your department are also a key source of peer mentors. Coursework provides a captive audience for building social capital necessary for your peer network. Building local peer networks can be as simple as asking a fellow student to chat over coursework or research over coffee or as involved as establishing a writing group with regular meetings where you read each other's work. You may also find mentors outside of your particular department on campus, especially in a broader school of Social Sciences or in the Humanities. This helps build networks around different topics or methodological approaches.

Mentors outside of your academic institution can also serve as a valuable source of information that is relevant for a wider range of situations. Formally, graduate students can participate in formal mentoring programs with the professional organizations listed at the end of this chapter to connect with mentors outside of their institution. Informally, finding a mentor can happen organically, such as through talking to fellow graduate students in your department/university or meeting someone at a conference panel or reception. Taking initiative, however, helps maintain these relationships by taking a single encounter and making it substantive.

We want to stress, however, that graduate students should not feel pressured to force a mentorship relationship with someone who is aggressive, unprofessional, or unsupportive. The most important feature of a mentoring relationship is that it provides productive support for the student. While mentors are there to provide advice, it can be difficult to accept that from someone that we do not trust to have our best interests at heart. More importantly, graduate students should not feel like the power imbalances require that they feel unsafe or suffer through 
disrespect, even if a potential mentor is "famous." Therefore, we strongly encourage graduate students to keep an open mind about who counts as a mentor and types of support. One person should not be your mentor for everything. Mentors are people too, with limits in time, energy, and capability.

Graduate students from under-represented backgrounds may not always have mentors who understand them. In some cases, a mentor might actively discourage these students or disregard how their circumstances influence their experience of the program. This should be a sign to widen your mentoring network and shift your expectations from that particular mentor.

Some students may worry that being proactive in developing mentoring relationships creates a burden for their mentors, especially mentors from under-represented backgrounds. However, these mentors often have invaluable expertise in navigating academia that can help students with similar backgrounds. This is also why we advocate for the network model, since it widens your community of support and reduces the likelihood of depending on just one or two people. Ultimately, mentors choose to participate in mentoring relationships, which may help alleviate some concerns about over-burdening, as well.

\section{When and How to Develop New and Existing Relationships}

There are many ways to develop one's mentoring network. Some will come naturally while others may feel awkward at first. Remember that network building and finding people who support you and your progress is a process. Begin as early as you can with the activities you are comfortable with. When you find a relationship that works well for you, invest in developing that relationship. Both the forms of network building and the substance of relationships change as you move across stages of graduate school. Below are actionable recommendations for how to develop mentoring relationships. 
- Be an active citizen of your department. Many mentoring relationships, especially at the beginning of your graduate career, are in your own department. Attend workshops, ask relevant questions, and set up meetings with visiting scholars. Meet with faculty in your department even if you are not taking their class.

- Invest in getting to know other graduate students in your department. Hear of a more advanced graduate student whose research is interesting? Ask them for a chat over coffee.

- Take advantage of conferences. Attend panels and ask questions, either during the panel or afterwards when people stand around and chat. Schedule a meeting with someone whose work interests you. Most people will be excited about your interest. One easy way to start building relationships is to have them talk about themselves and their work. Look for formal mentorship opportunities during conferences.

- Ask for introductions. If you know someone who knows someone you would like to meet, ask them for an introductory email. Finding relevant mentors can be particularly difficult for students from under-represented backgrounds. Even one relevant mentor can unlock a series of connections that can dramatically widen a mentee's network.

- Act in good faith. Some students, especially from under-represented backgrounds, may feel apprehensive about reaching out for guidance. If someone tells you to "let them know if you need anything," assume this is a genuine offer. Take a chance and reach out. If they seem unreceptive or unresponsive, move on to the next person.

\section{Conclusion}

This chapter has provided a categorization of who mentors are, what they can do, where to find them, when early scholars might need them, why mentorship matters, and how to build a supportive network. While not comprehensive, we hope that this approach clarifies the 
importance of being proactive about filling out a supportive network early in your graduate career and that mentorship is not solely a formal affair.

Every student is different and a network approach to mentorship allows students to identify and develop mentoring relationships based on their individual needs when they need it. Graduate students from under-represented backgrounds stand to benefit from cultivating their networks, since this can help them benefit from the experience and expertise of senior scholars. Mentors also have different preferences. Casting your net widely ensures that you have multiple sources of support for facing different challenges, an essential practice to ensure that you not only survive, but thrive in graduate school. 


\section{Resources}

\section{General Resources}

○ National Center for Faculty Development and Development: NCFDD Mentor $\underline{\text { Map }}$

- University of Washington's Graduate Mentoring Materials

○ Shives, K.D. 2012. "Picking a Good Mentor.” Inside Higher Ed. https://www.insidehighered.com/blogs/gradhacker/picking-good-mentor

○ On building peer reader mentoring relationships: Sarnecka, Barbara. 2021. The Writing Workshop

\section{Professional Organization Programs}

- APSA Mentor Program

- APSA Women's Research Mentoring Workshop

- ISA Committee on the Status of Women Pay it Forward Program

- WPSA Peer-to-Peer Mentors for Scholars of Politics, Groups, and Identities 


\section{References}

Argyle, Lisa P., and Tali Mendelberg. 2020. "Improving Women's Advancement in Political

Science: What We Know About What Works." PS: Political Science \& Politics 53 (4):718-722.

Cassese, Erin C, and Mirya R Holman. 2018. "Writing groups as models for peer mentorship among female faculty in political science." PS, Political Science \& Politics 51 (2):401.

Fugate, Gregory A., Patricia A. Jaramillo, and Robert R. Preuhs. 2001. "Graduate students mentoring graduate students: A model for professional development." PS, Political Science \& Politics 34 (1):132-133.

Lorenzetti, Diane L., Leah Shipton, Lorelli Nowell, Michele Jacobsen, Liza Lorenzetti, Tracey Clancy, and Elizabeth Oddone Paolucci. 2019. "A systematic review of graduate student peer mentorship in academia." Mentoring \& Tutoring: Partnership in Learning 27 (5):549-576. doi: 10.1080/13611267.2019.1686694.

Marino, Francesco E. 2020. "Mentoring gone wrong: What is happening to mentorship in academia?" Policy Futures in Education 19 (7):747-751.

Monroe, Kristen Renwick. "Mentoring in political science." PS: Political Science \& Politics 36, no. 1 (2003): 93-96. 